\title{
Study of knee angle in tribal children of Andhra Pradesh
}

\author{
Dhananjay Kumar', Patnaik V V Gopichand ${ }^{2}$, Nidhi Puri ${ }^{3}$ \\ ${ }^{1}$ Ph.D. Scholar, ${ }^{2}$ Professor \& Dean, ${ }^{3}$ Professor \& Head, Department of Anatomy, Maharishi Markandeshwar Institute of \\ Medical Sciences \& Research, Mullana, Ambala, Haryana, India
}

Background: Knee angle shifts from genu varum (bow leg) in newborn to neutral $\left(0^{\circ}\right)$ in infants and thereby, it becomes genu valgum (knock knee) in childhood as child begins to stand and walk. This sequential growth causes variation in gait and posture particularly up to 7-8 years of childhood stage. Aims and Objectives: This study establishes baseline data of knee angle in Indian tribal children of Andhra Pradesh. Despite its clinical importance and social relevance, literature is scanty in Indian population especially in tribal children. Materials and Methods: Tibiofemoral angle (TFA) was measured clinically using universal goniometer in 360 normal Indian tribal children of 2-14 years age group. Each age group comprised of 15 male and 15 female children. Height, weight, body mass index (BMI), thigh length (TL), leg length (LL) and lower limb length (LLL) were noted for all subjects to establish their relationship with TFA. Results: It was found that physiological varus rarely persists after 2 years of age. Beyond 2 years there was consistent increase in knee valgus. A maximum mean knee valgus of $8^{\circ}$ TFA was observed in girls at $6:<7$ years, while $6^{\circ}$ TFA was found in boys of $7:<8$ years age group. Thereafter progressive decrease in mean knee valgus of $5-6^{\circ}$ was seen up to $10:<11$ years age group which in later ages stabilizes to $6-7^{\circ}$ in both sexes. The overall pattern of knee valgus was found to be higher in girls than boys. Data revealed significant positive correlation between TFA and other parameters in both sexes at $p<0.05$ significance level. Conclusion: Age wise knee angle values for 2-14 year age group tribal children of Andhra Pradesh provided by this study could be of potential benefit to the physicians, orthopedic surgeons, pediatricians, radiologists, and physiotherapists while evaluating growth related shift patterns.

Key words: Knee angle, Tibiofemoral angle, Genu varum and Genu valgum, Goniometer

\section{INTRODUCTION}

Knee angle is also termed as tibiofemoral angle. ${ }^{1}$ Femoral neck overhangs the shaft such that the anatomical axes of femur and tibia do not coincide; but forms an angle called tibiofemoral angle (TFA). Alteration in the knee angle leads to genu varum and genu valgum also called as bowlegs and knock knees respectively.

Normal pattern of knee angle shifts from genu varum (bow leg) in newborn to neutral $\left(0^{\circ}\right)$ in infants and thereby, it becomes genu valgum (knock knee) in childhood as child begins to stand and walk. This sequential growth causes variation in gait and posture particularly up to 7-8 years of childhood stage. Most of the parents unaware of this physiological variation worry about their children. Knee angle in terms of TFA $\left({ }^{\circ}\right)$ is generally determined by photographic, ${ }^{2,3}$ radiological $^{1,4}$ and clinical $^{5-13}$ techniques. Clinical techniques are adopted in this study because of their reliability, easy applicability, and reproducibility. 3,7,9,11 Reliability of goniometric measurement of TFA was tested and agreed by many authors. ${ }^{11}$ It was thought to be reproducible enough in day to day practice.

Despite of its clinical importance and social relevance, literature is scanty on growth related shift patterns of knee angle in Indian population especially of tribal children. Previous studies emphasize ethnic variations in local 
population. ${ }^{1,3,5,7,9,14}$ So it is an attempt to set a base line data in tribal population of Andhra Pradesh state, India. In India most of the tribes are still in isolation, located mainly in the interior hills and forests which could not favor their all round development. They are most neglected and oppressed groups. In South India 6\% of tribal population was found in Andhra Pradesh and Karnataka. ${ }^{15}$ Gonds are one of the largest tribal groups in South Asia. Gonds belong to Dravidian stock occupying 5.1\% of Andhra Pradesh state population. Gonds constitute Koya, Konda reddy, lambadi tribes found mostly occupying Eastern ghats. Gond lifestyle has been that they did not transform from primitive farmers to urban, settled population until very recently. ${ }^{16}$ Of these Konda reddy tribe are of primitive tribal group. They were hunter gatherers but now they are settled agriculturists. They dwell mostly in hilly terrain. The Koyas, a tribal population largely, though not exclusively, concentrated in Andhra Pradesh, are the southernmost section of the great Gond race. The Lambadi tribe is one of the oldest tribes, inhabiting throughout the state of Andhra Pradesh.

\section{MATERIALS AND METHODS}

Institutional ethical committee clearance was obtained in prior to data collection. Procedure was explained and consent was also taken from parents/guardians/school authorities before conducting the study. It was a cross sectional study with sample size of 360 (180 girls and 180 boys) tribal children ranging in age from 2 to 14 years. They were randomly selected from different anganwadi, primary and middle schools of Andhra Pradesh state. Subjects were classified into twelve specific age groups. Each age group comprised 30 children (15 girls and 15 boys). Age in years was verified by documents from the schools or immunization cards in younger children. In case of lack of suitable documentation, regional festivals or lunar aspects described by parents regarding date of birth were taken into consideration. Only tribal children of 2 to 14 years age group from Andhra Pradesh were included which was strictly based on their origin of parents and grandparents. Children $<2$ years and $>14$ years, other than tribal of Andhra Pradesh, musculoskeletal disorders (developmental dislocation of hip, skeletal dysplasia, cerebral palsy, neuromuscular disorders, foot deformities, leg length discrepancy of $>2$ centimetres $(\mathrm{cm})$ ), surgery of lower limb were excluded.

Anthropometric variables such as height (cm), weight $(\mathrm{kg})$, TL $(\mathrm{cm})$, LL (cm), LLL (cm) were measured. Height and weight were measured with subject standing barefooted. Weight was measured to the nearest 0.5 kilogram $(\mathrm{kg})$ using a weighing scale which was set to zero reading before each measurement. Height was measured to the nearest $0.1 \mathrm{~cm}$ using a measuring tape. Tape was fixed to the wall to measure the height. The subject was made to stand with head held in Frankfurt's plane, feet placed together and the heels, buttocks and upper part of the back touching the tape. A ruler was firmly drawn down on to the vertex, crushing the hair as much as possible. Care was taken to watch that the feet do not come off the floor and that the position of the head is maintained in the Frankfurt plane. BMI was calculated by using the metric formula-(weight (kg) $\left.\times 10,000) /(\text { Height in } \mathrm{cm})^{2}\right)$. TL $(\mathrm{cm})$ was measured from the anterior superior iliac spine (ASIS) to the medial joint line of the knee and LL $(\mathrm{cm})$ was measured from the medial joint line of the knee to the tip of the medial malleolus. The sum of the above two were taken as the LLL. TFA was measured using goniometer in standing position with knee/ankle/both approximating closely. Hips and knees were in full extension with patellae straight ahead. Skin marks were placed as dots over the ASIS, centre of patella and the midpoint of the ankle joint (midpoint between the medial and lateral malleoli). Then two longitudinal lines one connecting ASIS and the centre of patella (femoral axis) and the other connecting the centre of patella and the midpoint of the ankle joint (tibial axis) were drawn using water soluble marker and the ruler (Figure 1a). The fulcrum of the goniometer was placed over centre of patella while the stationary arm along the femoral longitudinal axis and the movable arm on tibial longitudinal axis. The angle thus formed at the centre of patella by intersection between two longitudinal axes was noted as TFA (Figure 1b). The knee angle was assigned as negative for genu varum and positive value for genu valgum. All measurements were carried out by single researcher.

Statistical analysis was performed with help of SPSS version 16.0. A paired t-test was used to analyse differences

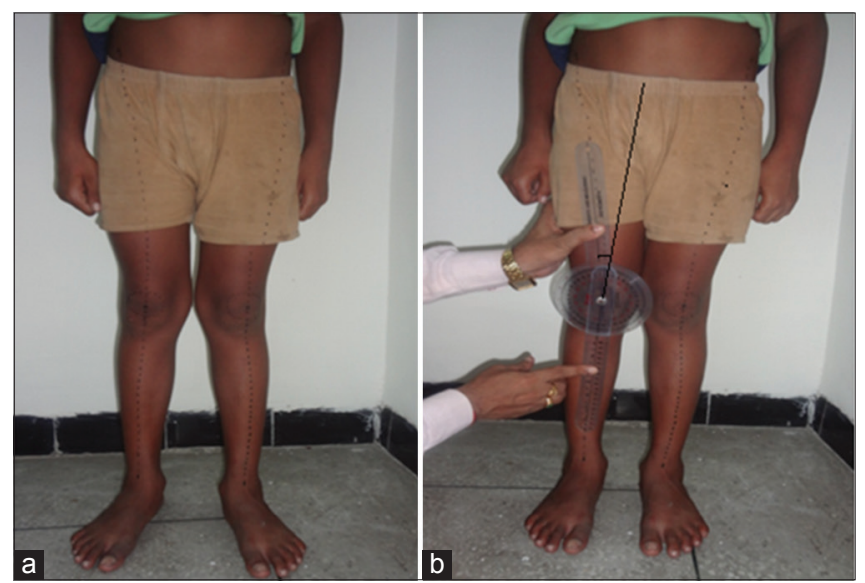

Figure 1: (a) Marking of centre of patella, femoral and tibial axis in standing position with full extension of knee, (b) Measurement of TFA with Goniometer 
between the right and left TFA of the lower limb. Independent $\mathrm{t}$-test was performed to assess differences between genders. Correlation of TFA with anthropometric variables were analysed using Pearson's correlation test. ANOVA was applied to test the differences of mean among all age groups as well as within age groups. If test was found significant then Post hoc was done to analyze the differences of mean between any two groups. P-value of less than 0.05 was considered to be statistically significant.

\section{RESULTS}

In order to assess intra-observer variability, intra-class correlation (ICC) was done on 20 children, (age group between 4-9 yrs) by measuring left TFA thrice at 24 hours interval. Mean intra class correlation coefficient (ICC) was 0.97 which was well in range of 0.94-0.99 showing perfect agreement and minimum intra observer variability as per typical interpretation of ICC value.

There was no statistically significant difference between right and left leg measurements as analysed by paired $t$ tests, so average was considered for further evaluation.

Mean height of $119.76 \pm 21.6 \mathrm{~cm}$, weight $21.88 \pm 9.7 \mathrm{~kg}$, BMI $14.28 \pm 2.29 \mathrm{~kg} / \mathrm{cm}^{2}$, TL $34.65 \pm 6.9 \mathrm{~cm}$, LL 28.28 $\pm 5.6 \mathrm{~cm}$, LLL $62.93 \pm 12.2 \mathrm{~cm}$ were observed.

Descriptive statistics of TFA were shown in Table $1 \&$ Figure 2 for 360 children. Mean knee angle at the age of 2 yrs was $1.48^{\circ}$ of valgus. A progressive increase in knee valgus was noted, with peak mean knee valgus of $6.60^{\circ}$ seen at 7-8 yrs of age. After the age of 8 yrs the angle stabilized to mean around $6^{\circ}$. Overall mean TFA was $5.29^{\circ}$. Maximum valgus of $14^{\circ} \mathrm{FA}$ was noted in $6:<7$ yrs age group.

Significant gender differences in FA were observed at $6:<7$ yrs of age $(p=0.023)$ and in overall $(p=0.022)$. Girls had higher valgus than boys in each age group (Table 2; Figure 3).

Mean knee angles in 180 male and 180 female tribal children at the age of $2 \mathrm{yrs}$ were $1.20^{\circ}$ and $1.78^{\circ}$ valgus. Thereafter, there was progressive increase in knee valgus with a peak of $6.47^{\circ}$ in males and $7.60^{\circ}$ in females. Maximum TFA value was observed as $12^{\circ}$ and $14^{\circ}$ at $7:<8$ and $6:<7 \mathrm{yrs}$ of age groups in male and female children respectively. It decreased to around $5^{\circ}$ in males and $6^{\circ}$ in females by 10 yrs. It stabilized later on to around $6^{\circ}$ and $7^{\circ}$ mean in male and female respectively. Overall mean TFA was $5.05^{\circ}$ and $5.65^{\circ}$ in 180 male and 180 female respectively (Table 2 \& Figure 3). The overall pattern of knee valgus was found to be higher in girls than boys.
Data established significant weak and positive correlation between TFA and age $(\mathrm{r}=.420)$, height $(\mathrm{r}=.463)$, weight $(\mathrm{r}=.395)$, BMI $(\mathrm{r}=.248)$, TL $(\mathrm{r}=.473)$, LL $(\mathrm{r}=.408)$, LLL $(r=.459)$ at $\mathrm{p}=0.000$ (Table $3 \&$ Figures $4-10)$.

\begin{tabular}{|c|c|c|c|c|c|c|}
\hline \multirow{2}{*}{$\begin{array}{l}\text { Age group } \\
\text { (years) }\end{array}$} & \multirow[t]{2}{*}{$\mathbf{N}$} & \multirow[t]{2}{*}{ Mean } & \multirow[t]{2}{*}{ SD } & \multirow[t]{2}{*}{ SEM } & \multicolumn{2}{|c|}{$95 \% \mathrm{Cl}$} \\
\hline & & & & & LB & UB \\
\hline $2:<3$ & 30 & 1.49 & 1.13 & 0.21 & 1.07 & 1.91 \\
\hline $3:<4$ & 30 & 3.19 & 2.13 & 0.39 & 2.40 & 3.99 \\
\hline $4:<5$ & 30 & 4.55 & 2.49 & 0.46 & 3.62 & 5.48 \\
\hline $5:<6$ & 30 & 5.35 & 2.06 & 0.38 & 4.58 & 6.12 \\
\hline $6:<7$ & 30 & 6.55 & 2.59 & 0.47 & 5.58 & 7.52 \\
\hline $7:<8$ & 30 & 6.60 & 2.41 & 0.44 & 5.70 & 7.50 \\
\hline $8:<9$ & 30 & 5.82 & 1.86 & 0.34 & 5.12 & 6.51 \\
\hline $9:<10$ & 30 & 5.37 & 1.86 & 0.34 & 4.67 & 6.06 \\
\hline $10:<11$ & 30 & 5.53 & 1.77 & 0.32 & 4.87 & 6.19 \\
\hline $11:<12$ & 30 & 6.20 & 1.81 & 0.33 & 5.52 & 6.88 \\
\hline $12:<13$ & 30 & 6.47 & 2.17 & 0.40 & 5.66 & 7.28 \\
\hline $13:<14$ & 30 & 6.45 & 2.07 & 0.38 & 5.68 & 7.22 \\
\hline Total & 360 & 5.29 & 2.52 & 0.13 & 5.03 & 5.56 \\
\hline
\end{tabular}

TFA: Tibiofemoral angle, ${ }^{\circ}$ : Degree, yrs-Years, Cl: Confidence interval, SD: Standard deviation, SEM: Standard error of mean, UB: Upper bound, LB: Lower bound, $\%$ : Percentage, N: Number

\begin{tabular}{|c|c|c|c|c|c|c|c|}
\hline \multirow{2}{*}{$\begin{array}{l}\text { Age } \\
\text { group } \\
\text { (years) }\end{array}$} & \multicolumn{2}{|c|}{$\begin{array}{c}\text { Male TFA } \\
\text { (degree) }\end{array}$} & \multicolumn{2}{|c|}{$\begin{array}{c}\text { Female TFA } \\
\text { (degree) }\end{array}$} & \multirow[t]{2}{*}{ t-value } & \multirow[t]{2}{*}{ DF } & \multirow[t]{2}{*}{ P-value } \\
\hline & Mean & SD & Mean & SD & & & \\
\hline $2:<3$ & 1.20 & 0.79 & 1.78 & 1.36 & -1.436 & 28 & 0.162 \\
\hline $3:<4$ & 2.65 & 1.70 & 3.73 & 2.42 & -1.418 & 28 & 0.167 \\
\hline $4:<5$ & 4.30 & 2.57 & 4.70 & 2.66 & -0.419 & 28 & 0.678 \\
\hline $5:<6$ & 5.16 & 2.08 & 5.53 & 2.09 & -0.480 & 28 & 0.635 \\
\hline $6:<7$ & 5.50 & 1.74 & 7.60 & 2.91 & -2.398 & 28 & $0.023^{*}$ \\
\hline $7:<8$ & 6.46 & 2.22 & 6.73 & 2.65 & -0.298 & 28 & 0.768 \\
\hline $8:<9$ & 5.30 & 1.80 & 6.33 & 1.82 & -1.559 & 28 & 0.130 \\
\hline $9:<10$ & 5.26 & 2.11 & 5.46 & 1.63 & -0.290 & 28 & 0.774 \\
\hline $10:<11$ & 5.13 & 1.82 & 5.93 & 1.66 & -1.253 & 28 & 0.221 \\
\hline $11:<12$ & 6.13 & 1.55 & 6.26 & 2.08 & -0.199 & 28 & 0.844 \\
\hline $12:<13$ & 6.10 & 1.79 & 6.83 & 2.49 & -0.923 & 28 & 0.364 \\
\hline $13:<14$ & 6.16 & 1.95 & 6.73 & 2.21 & -0.743 & 28 & 0.464 \\
\hline Total & 5.04 & 2.29 & 5.64 & 2.63 & -2.301 & 358 & $0.022^{*}$ \\
\hline
\end{tabular}

\begin{tabular}{lcc}
$\begin{array}{l}\text { Table 3: Correlation of TFA with various } \\
\text { anthropometric parameters }(\mathrm{N}=360)\end{array}$ \\
\hline Parameters & \multicolumn{2}{c}{ TFA } \\
\cline { 2 - 3 } & $\begin{array}{c}\text { Pearson correlation } \\
\text { value ( } \mathbf{r})\end{array}$ & Approx sig. \\
\hline Age & 0.420 & 0.000 \\
Height & 0.463 & 0.000 \\
Weight & 0.395 & 0.000 \\
BMl & 0.248 & 0.000 \\
Thigh length & 0.473 & 0.000 \\
Leg length & 0.408 & 0.000 \\
Lower limb length & 0.459 & 0.000 \\
\hline
\end{tabular}




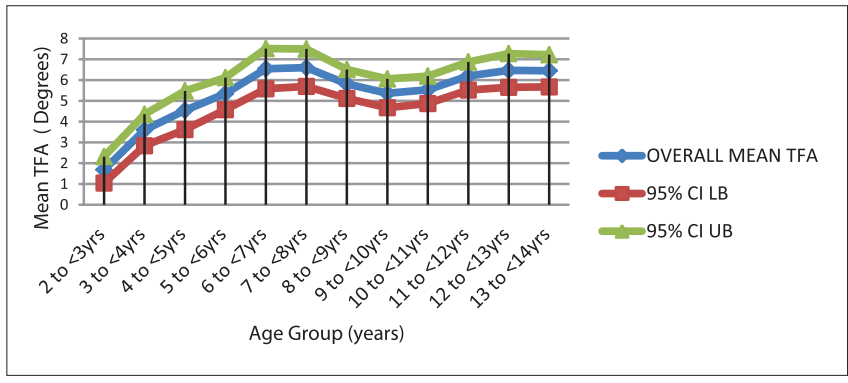

Figure 2: Baseline data for TFA with UB (+2SD) and LB (-2SD) age wise at $95 \%$ confidence interval

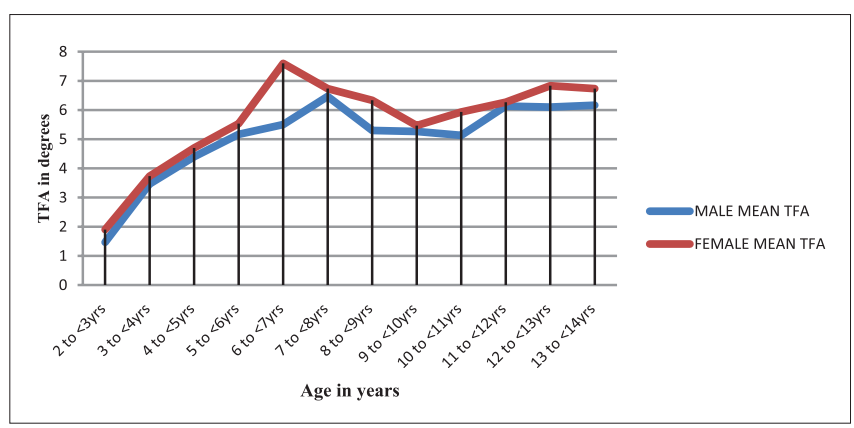

Figure 3: Comparison between male and female TFA

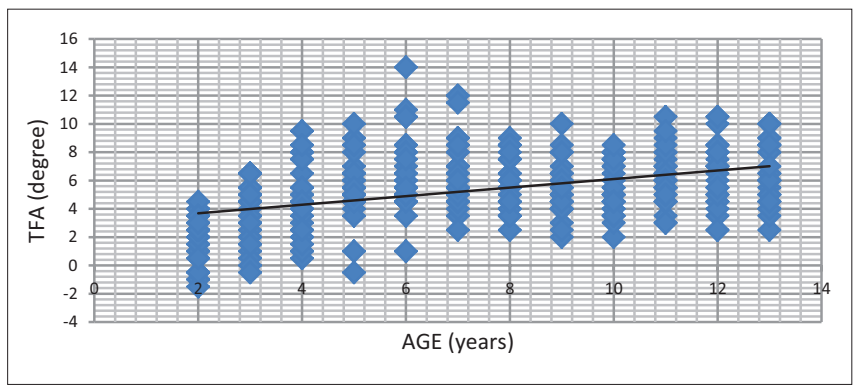

Figure 4: Relationship between TFA and age

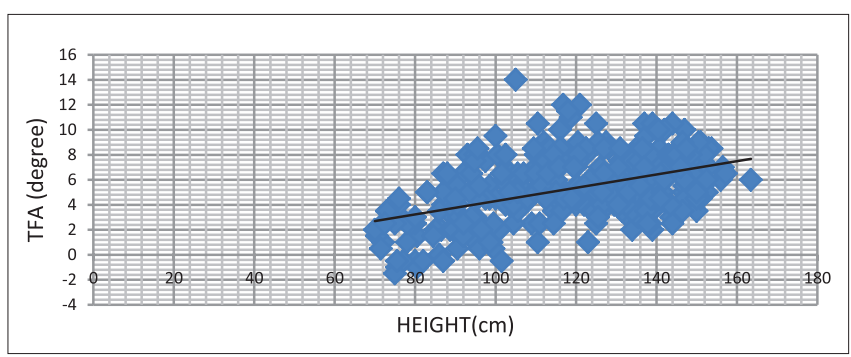

Figure 5: Relationship between TFA and height

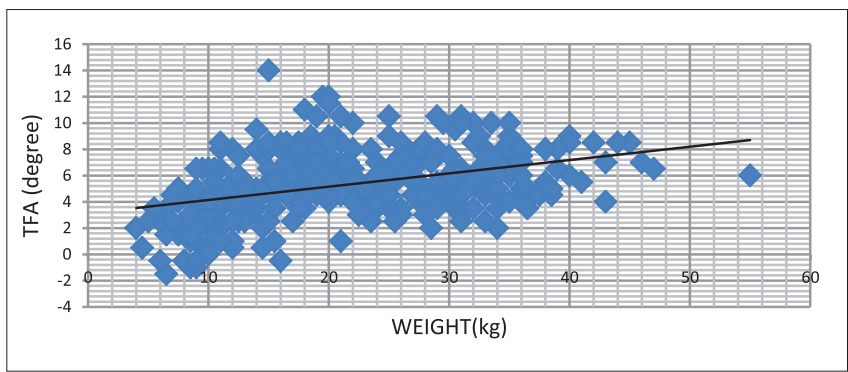

Figure 6: Relationship between TFA and weight

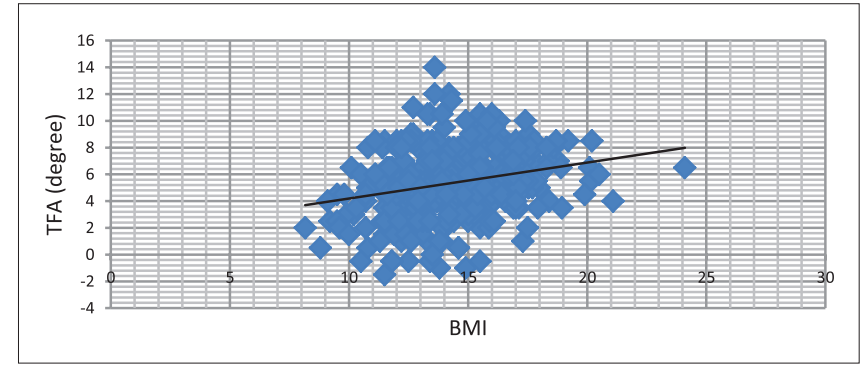

Figure 7: Relationship between TFA and BMI

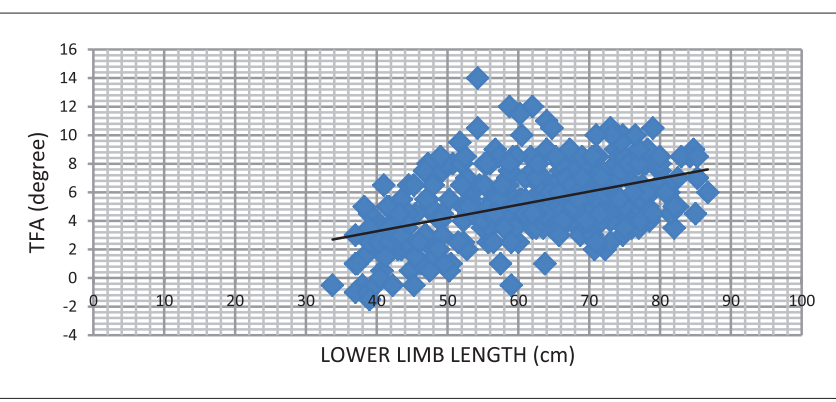

Figure 8: Relationship between TFA and lower limb length

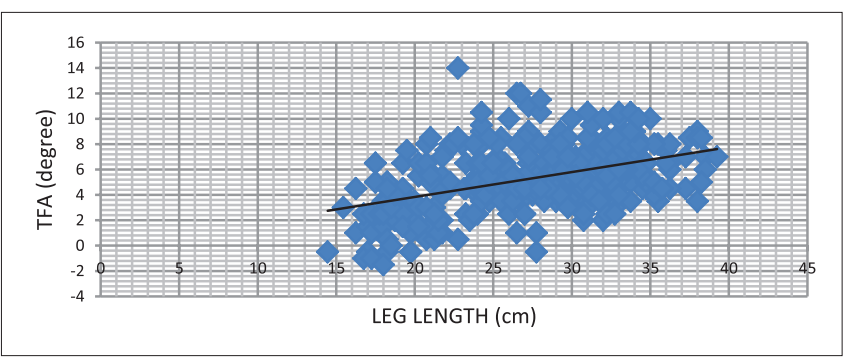

Figure 9: Relationship between TFA and leg length

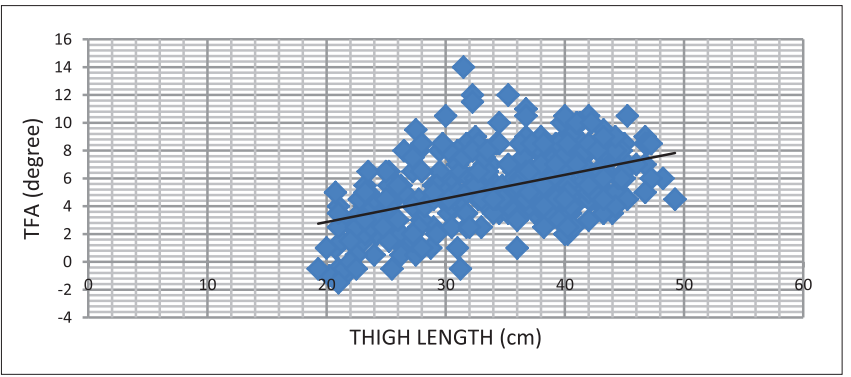

Figure 10: Relationship between TFA and thigh length

Table 4 showed significant differences in mean TFA among as well as within groups with F ratio $=14.770$ at $\mathrm{p}<0.000$. Post hoc multiple comparision test (Least Significant Difference) showed significant differences in mean TFA among $2:<3$ yrs and all other age groups. Mean TFA of 8: $<9$ yrs did not vary significantly with higher age groups (Table 5).

\section{DISCUSSION}

The normal development of the knee angle in children follows a definite pattern during growth. Knee angle

Asian Journal of Medical Sciences | Nov-Dec 2016 | Vol 7 | Issue 6 
initially shifts from varus to valgus and then transforms to mean peak valgus. Thereafter, the angle decreases to attain stable normal adult knee angle. These changes were previously reported to be dependent on age, ethnic and gender variations. ${ }^{12,14}$ Keeping these studies in view it was our attempt to establish base line data for knee alignment in indigenous tribal children. Population specific data would allow physicians, orthopaedic surgeons, paediatricians, radiologists, and physiotherapists to determine the knee alignment for reconstruction and management of varus and valgus deformities.

We noted $2 \% \& 1 \%$ varus, $2 \% \& 3 \%$ neutral and $96 \%$ $\& 97 \%$ valgus in male and female children respectively. Physiological varus beyond 2 yrs of age was found to be minimal. Physiological varus was seen up to $3:<4$ yrs of age in females and 5: $<6$ yrs in males. Our results were in agreement with previous Indian studies. ${ }^{12,13}$ Mathew et al. pointed out $2.7 \%$ of varus between $4-17$ yrs age which they considered to be pathological. ${ }^{13}$

Omololu quoted the occurrence of physiological varus till 7 yrs and peak varus was found between 1-3 yrs age. ${ }^{6}$ Some studies contradict the prevalence of varus in more than one year of age in Caucasian ${ }^{1,3}$ and Korean children. ${ }^{4}$ Varus confined up to 6 months of infants as reported in Caucasians and Nigerians. ${ }^{2,5}$ Our study observed more percentage of varus in males than females as shown by Mobarake et al. and Udoaka et al. ${ }^{17,18}$

\section{Table 4: ANOVA test for TFA $(\mathrm{N}=360)$}

\begin{tabular}{lccccc}
\hline Source & SS & DF & MS & F ratio & P value \\
\hline Between groups & 707.414 & 11 & 64.310 & 14.770 & 0.000 \\
Within groups & 1515.183 & 348 & 4.354 & & \\
Total & 2222.597 & 359 & & & \\
\hline
\end{tabular}

SS: Sum of squares, DF: Degree of freedom, MS: Mean square. Table denotes the significant differences of mean among all as well as within age groups
TFA increased consistently beyond 2 yrs in this study. After reaching peak valgus value TFA decreased to $5^{\circ}-6^{\circ}$ mean valgus at $10-11$ yrs age group. Later on the angle stabilized to $6^{\circ}-7^{\circ}$ in female and $5^{\circ}-6^{\circ}$ in male children till 14 yrs age group.

Significant gender differences in TFA $p=0.023$ in 6 to $<7$ yrs as well as $\mathrm{p}=0.022$ when all ages combined together were seen (Table 2). Saini ${ }^{12}$ observed significant gender differences in 3 yrs, 5 yrs \& 6 yrs age groups as well as in combined age groups where as Mathew ${ }^{13}$ found significant gender differences among individual age groups and in overall. Gender variations were also observed in Nigerian, Saudi and Turkish children. ${ }^{6,8,9}$ In contrary no gender variations were reported by some authors. ${ }^{1,3,4,19}$

Males had mean TFA of $5.04^{\circ}$ in comparison to $5.64^{\circ}$ in females (Table 2). High mean TFA of females was in accord with Mathew et al. ${ }^{13}$ who showed $4.05^{\circ}$ and $4.90^{\circ}$ in male and female children. Similar was the case with Saini in mixed Indian population who reported $4.6^{\circ}$ in male and $5.39^{\circ}$ in female children. ${ }^{12}$

Our results showed higher mean TFA than other two studies. Higher percentage of valgus beyond $2 \mathrm{yrs}$ indicates normal growth pattern of TFA in this study population (Figure 2).

Maximum mean knee valgus of $7.6^{\circ} \mathrm{TFA}$ in girls at 6-7 yrs and $6.46^{\circ}$ in boys at 7-8 yrs and overall mean of $6.6^{\circ}$ at 7-8 yrs was observed (Tables 1 and 2). Early occurrence of peak valgus at 5-6 yrs was previously reported in Indian children. ${ }^{12,13}$

Girls attained maximum peak valgus earlier than boys which was suggestive of early skeletal maturity in girls (Figure 3). Valgus angles were high in females than in

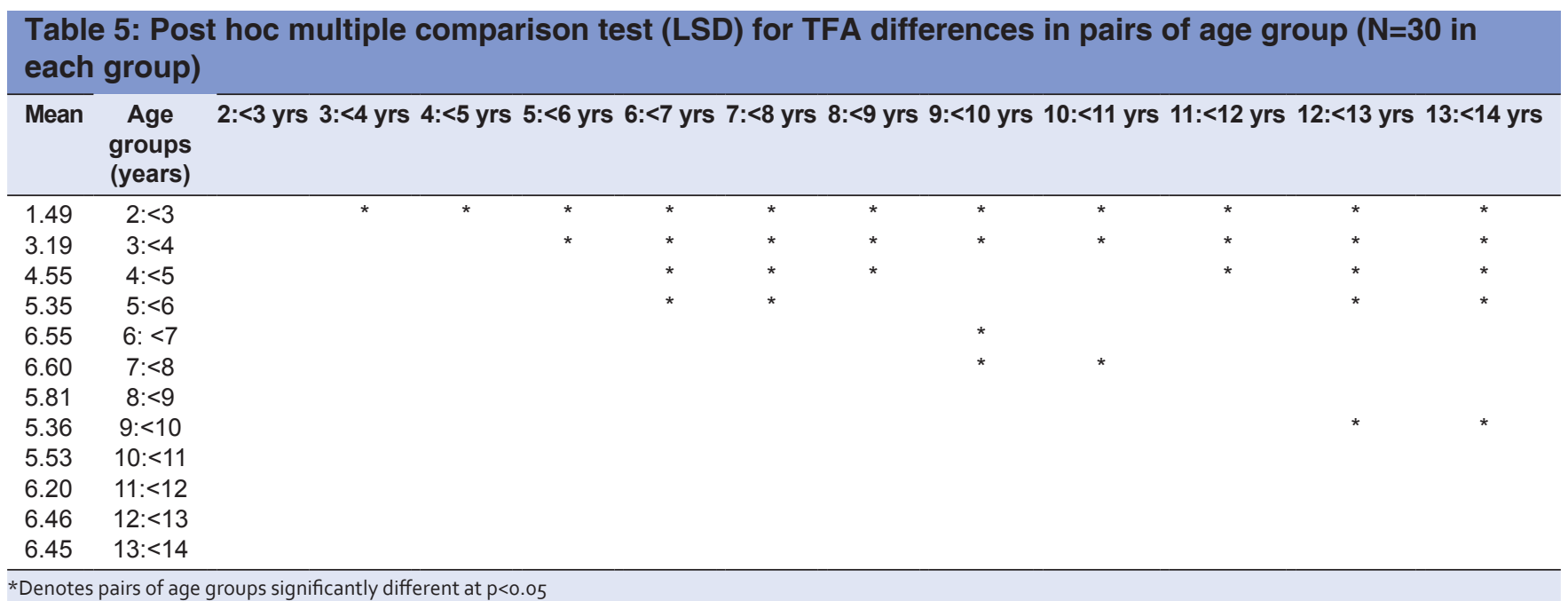


males which were well supported by several authors. ${ }^{5,12,13}$ Peak valgus obtained in our study was less in comparison to Saini. ${ }^{12}$ This might be due to the fact that the subjects included in their study belong to various parts of India. Our results were similar with those of Mathew et al as their study population included South Indian children. ${ }^{13}$ Other studies reported high mean peak valgus values in early ages than those reported in our study. Reports quoted $6.26^{\circ}$ at $3-4 \mathrm{yrs},{ }^{14} 7.87^{\circ}$ at $3 \mathrm{yrs},{ }^{20} 7.8^{\circ}$ at $4 \mathrm{yrs},{ }^{4} 8.4^{\circ}$ at $3 \mathrm{yrs},{ }^{21} 9.1^{\circ}$ at $2-3 \mathrm{yrs},{ }^{22} 9.8^{\circ}$ and $9.6^{\circ}$ at $6 \mathrm{yrs}$ and $7 \mathrm{yrs}$ in girls and boys repectively, ${ }^{9} 9.39^{\circ}$ in girls and $9.52^{\circ}$ in boys by $3-4$ yrs. $^{8}$

As the age advances, peak valgus decrease and attain stable adult values. TFA stabilized to $5^{\circ}-6^{\circ}$ after 8 yrs of age in our study population. Post hoc multiple comparisons showed significant differences in mean TFA among $2:<3$ yrs and all other age groups. Mean TFA of $8:<9$ yrs does not vary significantly with higher age groups. This indicates the stabilization of knee angle after this age. This study showed greater knee angle during stabilization when compared to other Indian studies.

When compared with previously quoted studies the TFA stabilized at $4.5^{\circ}-5^{\circ}$ in Indians after $10 \mathrm{yrs},{ }^{12} 3.18^{\circ}$ in boys and $4.43^{\circ}$ in girls at $17-18 \mathrm{yrs},{ }^{13} 5.5^{\circ}$ in girls and $4.5-5^{\circ}$ in boys between 10-16 yrs Europeans, ${ }^{11} 6^{\circ}$ in Nigerians after 6 yrs, ${ }^{5} 3.4^{\circ}$ at 8 yrs in Nigerians, ${ }^{21} 11^{\circ}$ constant from $1-10 \mathrm{yrs}$ age in both sex in Nigerians, ${ }^{6} 1^{\circ}$ at $10 \mathrm{yrs}$ in Nigerians, ${ }^{20} 0^{\circ}$ in Chinese, ${ }^{7} 5-6^{\circ}$ in Korean after 7-8 yrs of age, ${ }^{4} 6.6$ and 7.5 for boys and girls respectively at $17 \mathrm{yrs}$ in Turkish, ${ }^{\circ} 4^{\circ}$ after 7 yrs in Greek, ${ }^{14} 5-6^{\circ}$ after 7 yrs. ${ }^{22}$

This variability in stabilization of TFA among and within the regions indicates necessity for ethnic based studies.

Significant positive correlation was observed between TFA and other anthropometric variables (Table 3, Figures 4-10). This was in contrary to previous studies where negative correlation was observed. It might be due to peak mean valgus observed in early ages.

The shift form varus to valgus in a growing human knee depends on growth of articular cartilages and development at the growth plates in the distal end of femur and proximal end of tibia. As children start to walk, they like to hold their feet wide apart to increase stability. Due to this pressure is applied on the lateral side of knees. It allows medial part of the epiphyseal plate to grow faster which causes laxity of medial ligament of knee increasing the amount of valgus. Change in angle of lower end of femur and upper end of tibia may be a cause for shift of varus to valgus. Laxity occurs in anterior cruciate ligament due to different life style like downhill walking, playing football and so on. Variation in different terrain may play a role in bone morphology from region to region specifically at proximal tibia, distal femur, patellar grooves.

Women have smaller and narrower knees with smaller mediolateral/anteroposterior ratio. Smaller the radius of curvature greater will be range of motion. Women have broader pelvis, so angle of valgus is more.

The reason for above said variations may be due to differences in life style and terrain of the area, in which study was conducted, different techniques used in estimation of knee angle. The ethnic and racial differences suggest the need for age specific reference values in local population.

Children showing varus alignment of the knee after 3 yrs of age might be atypical and requires radiological evaluation, regular follow-up and proper management. We evaluate that a valgus angle of up to $12^{\circ} \& 14^{\circ}$ might be normal in Indian children in the age group of 6-7 \& 7-8 yrs in male $\&$ female respectively and needs only observation.

We have also provided $95 \%$ CI of the mean TFA in each age group and these values can be used as a range of reference for Indian tribal children in future follow up studies.

\section{CONCLUSION}

Age wise normal values and range of knee angle for 2-14 yrs age group tribal children of Andhra Pradesh provided by this study could be of potential benefit to the physicians while evaluating growth related shift patterns. The knowledge of normal range of TFA in specific population is essential in reconstruction and management of knee varus and knee valgus deformities for orthopedic surgeons, pediatricians, radiologists, and physiotherapists.

\section{REFERENCES}

1. Yoo JH, Choi $\mathrm{IH}$, Cho TJ and Yoo WJ. Development of tibio femoral angle in Korean children. J Korean Med Sci 2008;23(4):714-717.

2. Engel GM and Staheli LT. The natural history of torsion and other factors influencing gait in childhood: A study of the angle of gait, tibial torsion, knee angle, hip rotation and development of the arch in normal children. Clin Orthop Relat Res 1974; 99:12-17.

3. Heath $\mathrm{CH}$ and Staheli LT. Normal limits of knee angle in white children: Genu varum and genu valgum. J Pediatr Orthop 1993;13(2):259-262.

4. Salenius $P$ and Vankka $E$. The development of the tibiofemoral angle in children. J Bone Joint Surg [Am] 1975; 57A (2):259-261.

5. Oginni LM, Badru OS, Sharp CA, Davie MW and Worsfold M. Knee angles and rickets in Nigerian children. J Pediatr Orthop 2004;24(4):403-407.

6. Omololu B, Tella A, Ogunlade SO, et al. Normal values of knee 
angle, intercondylar and intermalleolar distances in Nigerian children. West Afr J Med. 2003;22(4):301-304.

7. Cheng JCY, Chan PS, Chiang SC, et al. Angular and rotational profile of the lower limb in 2630 Chinese children. J Pediatr Orthop. 1991;11(2):154-161.

8. Rahman SA, Badahdah WA. Normal development of the tibiofemoral angle in Saudi children from 2 to 12 years of age. World Appl Sci J. 2011;12(8):1353-1361.

9. Arazi M, Oğün TC, Memik R. Normal development of the tibiofemoral angle in children: a clinical study of 590 normal subjects from 3 to 17 years of age. J Pediatr Orthop. 2001;21(2):264-267.

10. Oyewole OO, Akinpelu AO, Odole AC. Development of the tibiofemoral angle in a cohort of Nigerian children during the first 3 years of life. J Child Orthop. 2013;7(2):160-173.

11. Cahuzac JP, Vardon D, Sales de Gauzy J. Development of the clinical tibiofemoral angle in normal adolescents: A study of 427 normal subjects from 10 to 16 years of age. J Bone Joint Surg [Br]. 1995;77(5):729-732.

12. Saini UC, Bali K, Sheth B, Gahlot N, Gahlot A. Normal development of the knee angle in healthy Indian children: A clinical study of 215 children. J Child Orthop. 2010;4(6):579-586.

13. Mathew S.E, Madhuri V. Clinical tibiofemoral angle in south Indian children. Bone Joint Res. 2013;2(8):155-161.

14. Kaspiris A, Grivas TB, Vasiliadis E. Physiological alignment of the lower limbs changes during childhood: A clinical study in south-west Greece. Adv Biomed Res. 2010;1:249-251.

15. Cavalli-Sforza LL, Menozzi P, Piazza A. The history and geography of human genes. United States of America: Princeton University Press, 1994;p.212.

16. Vahia MN, Halkare G. Aspects of Gond astronomy. J Astron Hist and Herit. 2013;16(1):29-44.

17. Mobarake MK, Kashefipour, Yousfnejad Z. The prevalence of genu varum and genu valgum in primary school children in Iran 2003-2004. J Med Sci. 2005;5(1):52-54.

18. Udoaka Al, Olotu, Oladipo GS. The prevalence of genu varum in primary school children in Port Harcourt, Nigeria. Sci Afr. 2012;11(2):115-117.

19. Fakoor M, Safikhani Z, Razi S, Javaherizadeh H. Study of knee angle development in healthy children aged 3-16 years in Ahwaz, Iran. Int J Orthop Surg. 2009;16(1):1-5.

20. Bafor A, Omota B, Ogbemudia AO. Correlation between clinical tibiofemoral angle and body mass index in normal Nigerian children. Int Orthop. 2012;36(6):1247-1253.

21. Omagbegmi DOO, Odunubi OO, Ugweogbulem OA. Angular profile of the knees of Nigerian children in Lagos, Nigeria. Afr J Trop Med Biomed Res. 2012;1(3):18-26.

22. Sabharwal S, Zhao C, Edgar M (2008) Lower limb alignment in children: Reference values based on a full-length standing radiograph. J Pediatr Orthop. 2008;28(7):740-746.

Authors Contribution:

DK - Conducted the study, data collection and analysis, manuscript preparation; PVVG - Concept, planning, study design, critical appraisal; NP - Concept, planning, review of manuscript.

Source of Support: Nil, Conflict of Interest: None declared. 